\title{
DEMOCRACIA Y COMUNICACION EN EL SALVADOR
}

\author{
Carlos Ayala Ramírez*
}

\section{Introducción}

U

na de las principales necesidades y demandas que tienen hoy las sociedades que protagonizan procesos democráti cos, es lograr que éstos (procesos) pasen realmente por la comunicación. El vínculo entre democracia y comunicación alude a algo mucho más profundo, que las nociones que terminan por identificarla o reducirla a la mera libertad de expresión o de prensa. ¿En qué consiste la democratización de la comunicación y qué supone una comunicación democrática? son las preguntas fundamentales que pretendemos responder en este breve escrito. Cuatro son los puntos que configuran nuestra respuesta: primero, examinaremos el grado de incidencia de los procesos democráticos en la comunicación -específicamente el derivado a partir de los acuerdos de paz-; segundo, haremos una descripción teórica de lo que implica y supone el ejercicio de los derechos a la expresión y a la comunicación; tercero, estableceremos algunas limitaciones y alcances implícitos en la formulación teórica y, cuarto, enunciaremos algunas condiciones básicas, sin las que no se puede dar una realización efectiva de la comunicación democrática.

\section{La democratización: nuevo contexto de la comunicación}

Toy día, vivimos una época de revalorización de la democracia, 1 Lentendida ésta como: proceso, régimen político y proyecto de sociedad. Democracia como proceso quiere decir que sus exigen-

- Director de la Radio YSUCA. 
cias no son invariables en el tiempo, sino que van aumentando progresivamente; significa también, el fortalecimiento permanente de las instancias y de los mecanismos civiles que garantizan una participación de los diversos sectores e individuos, con el fin de ir construyendo relaciones $\mathrm{e}$ instituciones verdaderamente democráticas.

Por su parte, los rasgos que diferencian y caracterizan a la democracia como régimen político, son: el Estado de derecho, la división e independencia de poderes, la soberanía popular expresada en el sufragio universal, la altemancia en el poder, el pluralismo político, la vigencia plena y real de las libertades públicas y la garantía de los derechos humanos en general (Samour, 1994). Claro está, que estas características deben verificarse en la realidad histórica, para medir su grado de realización, y así superar interpretaciones puramente abstractas que suelen identificar el deber ser con la realidad. Hablar de un régimen político democrático significa, por tanto, hacer referencia a un conjunto de normas de procedimiento y reglas de juego que sirven para resolver, por la vía de la mayoría y con el respeto a las minorías, los conflictos de intereses que inevitablemente se producen en toda sociedad (ver Oller, 1994).

La democracia como proyecto de sociedad, en cambio, va más allá de la mera gobernabilidad política. Esta supone consolidar los valores democráticos en el ámbito social, económico y cultural. Históricamente hablando - y desde la perspectiva de sociedades como la salvadoreña- esto significa la salvaguarda y garantía de los derechos socioeconómicos de las mayorias. Estas últimas pueden tipificarse de la siguiente manera: (1) son la mayor parte de la sociedad, que vive en unos niveles en los que apenas pueden satisfacer las necesidades básicas; (2) son aquellas mayorías que no sólo llevan un nivel material de vida que no les permite un suficiente desarrollo humano, sino que se encuentran marginadas frente a unas minorias que utilizan en su provecho los recursos disponibles; (3) son aquellas mayorias que no están en condiciones de desposeídas por leyes naturales o por desidia personal o grupal, sino por ordenamientos sociales históricos que les han empobrecido (ver Ellacuría, 1982).

Estas diferencias conceptuales entre proceso, régimen político y proyecto de sociedad en tomo a la democracia, se hacen necesa- 
rias no sólo para compiender la realidad y el sentido de los procesos sociales, sino también -y este es el objetivo de nuestras reflexiones- para conocer los modos y grados de influencia de los espacios democráticos en la comunicación y, a su vez, para indagar cómo ésta (la comunicación) puede contribuir a consolidar tales procesos.

En el caso de El Salvador, diversos análisis coinciden en que los Acuerdos de Paz, abrieron una fase de primera importancia para la historia del país. Cuatro fueron los objetivos que se propusieron las partes negociadoras: terminar con el conflicto amado por la vía política; garantizar el irrestricto respeto a los derechos humanos; impulsar la democratización y reunificar a la sociedad salvadoreña.

Vistos retrospectivamente, los acuerdos han posibilitado la transformación de algunas instituciones y estructuras que podrían llevamos al establecimiento de un régimen democrático. Citemos algunos logros en este sentido: superación definitiva de la guerra, redefinición de las funciones constitucionales y la doctrina militar de la Fuerza Armada, creación de la Procuraduría de Derechos Humanos, reformas del Código Electoral, conformación del nuevo Tribunal Supremo Electoral, legalización del FMLN como partido político, readecuación del Sistema Judicial, sustitución de los antiguos cuerpos policiales por la nueva Policía Nacional Civil. No olvidamos, por supuesto, que los acuerdos tienen serias limitaciones, una de las principales es lo poco que se negoció sobre el otro gran problema de la realidad nacional: la injusta estructura económica imperante. Así mismo, en lo que toca al tema objeto de nuestras reflexiones (la democratización de la comunicación) fue mínimo lo que se logró avanzar. En el acuerdo de San José sobre Derechos Humanos (julio de 1990), sólo se hacen dos referencias muy generales: en el numeral 5 se afirma que se dará plena garantía al derecho de todas las personas de asociarse libremente con fines ideológicos, religiosos, políticos, económicos, laborales, sociales, culturales, deportivos o de cualquier otra índole; el numeral 6 expresa, que se dará plena garantía a la libertad de expresión y de prensa, al derecho de respuesta y al ejercicio del periodismo.

Los acuerdos de Chapultepec, por su parte, hacen también referencia al tema, pero sólo en lo que respecta a la participación polí- 
tica del FMLN. Específicamente, se habla de la autorización de licencias para medios de comunicación social; del derecho a la instalación de infraestructura apropiada (locales, imprentas, etc.); de la libertad para la publicación de campos pagados en los medios de difusión, por parte del FMLN.

Hay que señalar además, que de las varias reformas constitucionales gestadas en el proceso de negociación, con el fin de sustentar los acuerdos políticos, ninguna de ellas apuntó a la democratización de la comunicación. Los acuerdos de paz, pues, aunque generaron ciertos cambios en esta área, tales como: fin al control de los medios y a la censura, suspensión de la actividad "reguladora" que realizaba la Oficina de Información de la presidencia sobre los periodistas nacionales y extranjeros, mayor pluralismo en la información, mayores espacios de debates y el compromiso de contribuir, a través de los medios, al proceso de distensión y reconciliación nacional. No obstante, todo ello, el tema de la comunicación y la expresión como derechos de la sociedad civil, sigue ausente.

Por consiguiente, uno de los puntos pendientes para hablar de régimen democrático, lo constituye la democratización de la palabra, esto es, liberalización de los flujos informativos,igualdad de oportunidades, posibilitar la participación ciudadana, irrestricto acceso a canales y espacios.

Junto a estas limitaciones, el proceso de democratización enfrenta una serie de obstáculos, provenientes, sobre todo, de aquellos actores sociales de trayectoria antidemocrática. Hay por lo menos siete obstáculos autoritarios que enfrenta el proceso de transición: la militarización del Estado y la sociedad (todavía no del todo superada); una estructura del aparato estatal burocratizada y desfasada; la limitación de los espacios de participación social y política; el control de los medios de comunicación por los sectores económicamente poderosos; el predominio de una cultura política autoritaria; la desintegración social y la atomización de las acciones de la sociedad civil; y, finalmente, la alta concentración de la riqueza (Samour citando a Lungo,1994).

A estos males hay que agregar el incumplimiento y distorsión de algunos acuerdos, el crimen organizado, la impunidad y la corrupción que predomina en el país. En el proceso de democratiza- 
ción, pues, subsisten actores, instituciones y actitudes antidemocráticas. La cizaña sigue estando junto al trigo $\mathrm{y}$, peor aún, hay cizaña que lleva el nombre de trigo. Por eso, uno de los principales retos de las fuerzas democráticas es consolidar y profundizar la letra y el espíritu de los acuerdos de paz. El cumplimiento cabal de éstos, es condición básica para modificar la estructura de poder en beneficio del bien común. Es cierto que la sola fuerza de los acuerdos de paz no nos llevarán inevitablemente a la democratización, ni mucho menos a la instauración de una democracia integral (social, económica, cultural); pero sí, son una buena base para salir de una democracia de fachada o formal, hacia un régimen político que supere el autoritarismo, el oficialismo y la arbitrariedad.

Antes de las elecciones de 1994, se creía que éstas representaban la culminación del proceso de paz. En parte por eso se sostenía que eran las "elecciones del siglo". Los críticos de este planteamiento argumentaban que las elecciones podrían haber sido del siglo, sólo sí hubiesen cumplido con las siguientes condiciones: contribuyen a solucionar los grandes problemas del país o al menos se convierten en un inicio de solución; son expresión cuantitativa de una voluntad popular consciente; son totalmente transparentes; y, propulsoras de los acuerdos de paz (ver ECA, septiembre, 1993). Sin embargo, después de las elecciones las evidencias empíricas mostraron que éstas no fueron limpias, transparentes, libres, ni masivas. Las elecciones no sólo no fueron del siglo, sino que -a causa de sus múltiples anomalías- poco aportaron al proceso de democratización. El acontecimiento político más trascendental de la época, por tanto, sigue siendo el relacionado con los acuerdos de paz. El diálogo, la negociación y los acuerdos de paz han resultado más democratizadores de la sociedad salvadoreña, que todos los procesos electorales realizados en los últimos doce años. Esto no sólo porque ha posibilitado la participación de buena parte de la sociedad civil, sino sobre todo - como señalamos arriba- porque pusieron fin al conflicto armado e iniciaron la transformación de instituciones y estructuras de larga historia antidemocrática.

Los acuerdos de paz, pues, abren posibilidades concretas para transformar la sociedad salvadoreña en una sociedad democrática. Esto si consideramos no sólo sus potencialidades inmediatas, sino 
sobre todo, sus potencialidades a mediano y largo plazo que pueden desembocar en el predominio de la sociedad civil sobre el estamento militar; terminar con la impunidad e impulsar una auténtica administración de justicia; propiciar una actividad política más pluralista; posibilitar la participación y distribución equitativa del poder social; garantizar a las mayorías el acceso al trabajo, a los recursos productivos, a la educación, la salud, la vivienda y a la libre comunicación y expresión.

\section{La comunicación en un contexto democrático}

Fl derecho a la expresión está explícitamente reconocido en la en el artículo 19 que estipula lo siguiente: "Todo individuo tiene derecho a la libertad de opinión y de expresión; este derecho incluye no ser molestado a causa de sus opiniones, el buscar, recibir y difundir información e ideas por cualquier medio de comunicación y sin limitación de fronteras".

La Constitución Política de El Salvador, en su artículo 6 consagra también este derecho: "Toda persona puede expresar y difundir libremente sus pensamientos siempre que no subvierta el orden público, ni lesione la moral, el honor, ni la vida privada de los demás. El ejercicio de este derecho no estará sujeto a previo examen, censura ni caución; pero los que haciendo uso de él, infrinjan las leyes, responderán por el delito que cometan...".

En lo que respecta al derecho de la comunicación, si bien la Declaración Universal de Derechos Humanos y la Constitución Política de El Salvador, no lo consagran explícitamente; si podemos encontrar en los artículos arriba mencionados, elementos básicos que fundamentan su necesidad. Claro está, que el derecho a la comunicación no sólo implica derecho de recibir y difundir información, sino que demanda a su vez otro conjunto de derechos: (1) los relacionados con la asociación (derecho a reunirse, a participar, a escuchar y ser escuchado; derecho a réplica, a ver y ser visto); (2) los relacionados con la evolución cultural (derecho a un idioma, a relacionarse con otras culturas, al respeto de los propio valores).

En el contexto de un régimen democrático, estos derechos - al igual que todos los contenidos en la Declaración Universal y en la 
Constitución Política, tienen sus restricciones razonables. En el caso de la libre expresión y la libre comunicación, sólo están limitados por el respeto a los derechos o la reputación de los otros y por la protección de la seguridad nacional bien entendida, es decir, evitando que estos derechos degeneren en odio nacional o en discriminación racial, sexual, religiosa, política, etc.

En este planteamiento formal y legal del derecho a la libre expresión y comunicación, encontramos importantes valores que pueden ser potenciados en favor de la democratización. En primer lugar, hay un reconocimiento de que ambos derechos son primarios y no derivados (secundarios); esto significa que son inherentes a la persona humana, pertenecen al ser humano en cuanto tal $y$, en consecuencia, su conservación, fomento y difusión se constituyen en un imperativo, ya que en su vigencia se pone en juego parte de la realización humana.

En segundo lugar, si el derecho de expresión, de información y de comunicación son fundamentales para la convivencia y la realización humana, habrá que garantizarlos a todas las personas y grupos sociales. El respeto (por parte del estado) y la práctica (por parte de los ciudadanos) de estos derechos, se constituyen en uno de los criterios verificadores de la presencia o ausencia de una efectiva democracia. Sobre todo, cuando el origen y la vigencia de esos derechos, busca asegurar el ejercicio real de la libre expresión y comunicación, a los sectores que por su condición social o económica, han sido históricamente marginados. El derecho a la libre expresión y comunicación, pues, no es exclusivo ni privativo de los profesionales de la comunicación (periodistas o comunicólogos), ni mucho menos de los propietarios de los medios o de los grupos de poder. Es ante todo, un derecho de la sociedad civil, así lo establecen las normas constitucionales del país y la declaración universal de derechos humanos.

En tercer lugar, en el planteamiento formal y legal queda muy claro, que un ejercicio efectivo de estos derechos, supone e implica la democratización de los medios de comunicación. El uso de los medios, en un sistema democrático, no tiene porque ser ser exclusivo de un sector, de una ideología o de un sólo tipo de intereses. La compatibilidad entre comunicación y democracia supone la posibilidad real de acceso a canales y espacios, la igualdad de oportu- 
nidades y la pluralidad de flujos informativos. Democratizar el uso de los medios implica dejar sentir la palabra de la mayor parte de la población (las mayorías) y darle un marco legal a esa voz de la sociedad civil (legitimarla).

Ahora bien, junto a estos aspectos positivos que debemos operativizar de cara a fortalecer el proceso democrático, existen serios peligros que tenemos que conocer y superar para que proceso no se desnaturalice.

Uno de los peligros más graves de todos los derechos considerados universales - los aquí analizados no son la excepción- es su interpretación puramente formal (abstracta), que no tiene en cuenta la práctica real de los mismos. Es el caso, por ejemplo, de todos aquellos "defensores" de las declaraciones universales o de los principios constitucionales, que en ningún momento examinan o verifican cuántos y de qué modo ejercen los derechos proclamados en los principios. Se quedan en el discurso, dando por supuesto que lo que se dice en él, se da o debe darse en la realidad. A las personas, grupos sociales o instituciones que así piensan, hay que recordarles que no basta con defender los principios abstractos, no basta con hacer apología de los derechos en sí. Es necesario examinar el ámbito de las circunstancias concretas para verificar si éstas ofrecen o no condiciones reales para la práctica colectiva de los derechos (por ejemplo la libre expresión y la libre comunicación). Esto implica determinar quién o quiénes pueden exponer o difundir, de hecho, su pensamiento; qué tipo de pensamiento es el que tiene posibilidades de llevarse a la práctica, sin restricciones u obstáculos; a qué intereses responde ese pensamiento cuya circulación se permite y se favorece.

Sin verificación histórica, las formulaciones abstractas pueden convertirse en mecanismo ideológico, que vendría a ocultar una realidad que de suyo niega lo que proclama el derecho. Es decir, la realidad de que el derecho universal (de libre expresión y comunicación) es un privilegio de pocos, ya que son minorías las que cuentan con las condiciones reales para hacerlos efectivos. Cuando el derecho de todos se convierte en privilegio de pocos, se atenta contra el bien común y, por consiguiente, contra la democracia. Esto es justamente, lo que ha ocurrido en los regímenes con una democracia puramente formal o con una fachada democrática bien 
montada, donde los supuestos avances o defensa de los valores democráticos, no están en función de la participación popular y ciudadana, sino al servicio de la cobertura y protección de estructuras fundamentalmente antidomocráticas.

Pero, este peligro, puede y debe ser superado desde y en los procesos de democratización. Ignacio Ellacuría (Ellacuria, 1990), señalaba dos modos básicos para enfrentar esta grave limitación: primero, hay que ver cómo se está realizando en una circunstancia dada, lo que se afirma abstractamente como "deber ser" de los derechos humanos (para el caso de la libre expresión, de la libre comunicación); segundo, hay que plantear y crear aquellas condiciones reales, sin las que no se puede dar una realización efectiva de lo que se anuncia como lo mejor posible para nuestra realidad (cuantificar y verificar las proclamaciones ideales en orden a saber cuándo pueden convertirse en realidades o alcanzar, al menos, cierto grado aceptable de realización).

Intentemos seguir este planteamiento en el tema que hoy nos ocupa. En la realidad de nuestro país, ¿cuál ha sido y es el grado de vigencia del derecho a la comunicación y a la expresión? Tal y como funcionan actualmente los medios de comunicación colectiva, ¿contribuyen a fortalacer el proceso democrático? ¿Qué frena o posibilita la participación de la sociedad civil en el ámbito de la comunicación? ¿En qué consiste la práctica del fin social de los medios?

Decíamos arriba que la libertad de comunicación y de expresión, suponen la puesta en práctica del conjunto de derechos civiles y políticos. Pues bien, durante los casi doce años que duró el conflicto armado, hablar de violación de los derechos humanos en El Salvador, era hacer referencia explícita a este conjunto de derechos gravemente conculcados. El Informe de la Comisión de la verdad (ver De la locura a la esperanza, 1993), considerado el documento oficial más importante en la historia reciente del país, da pruebas suficientes para sustentar nuestra afirmación. En la parte denominada "Cronología de la violencia", el Informe nos describe cuatro momentos de graves violaciones a los derechos civiles y políticos.

Primer periodo (1980-1983), se instaura de manera sistemática la violencia, el terror y la desconfianza en la población civil. Se pro- 
cede a la desarticulación de cualquier movimiento opositor o disidente por medio de detenciones arbitrarias, asesinatos, desaparición selectiva e indiscriminada de dirigentes. La represión en la ciudad se dirigió contra las origanizaciones políticas, los gremios y los sectores organizados de la sociedad salvadoreña.

Segundo periodo (1983-1987), continuaron las violaciones a la vida, la integridad física y la seguridad en los centros urbanos. Así mismo, el desarrollo militar de la guerra llevó a la Fuerza Armada a visuálizar a la población civil de las zonas en conflicto como "objetivos legítimos de ataque". La recurrencia sistemática de esta práctica produjo un efecto que carecteriza a esta etapa: legiones de desplazados y refugiados.

Tercer periodo (1987-1989), se avanzó en lo que la comunidad internacional denominó "la humanización del conflicto" (suspensión de bombardeos, ataques indiscriminados, secuestros, etc.). Sin embargo, la violencia resurgió con un claro incremento de los ataques al movimiento laboral, a los grupos de derechos humanos y a las organizaciones sociales.

Cuarto periodo (1989-1991), se desencadenó la mayor ofensiva registrada a lo largo del conflicto, ésta ocurrió a los pocos días del atentado con dinamita en la sede de FENASTRAS. La magnitud de la ofensiva sobre la capital y otras ciudades, llevó a decretar el estado de excepción. Durante la ofensiva se materializaron violaciones como la detención, la tortura, el asesinato y la desaparición de cientos de personas de la población civil no combatiente. Luego de los combates, las partes reconocieron la imposibilidad de una victoria militar decisiva y se retomó con mayor ahínco el proceso de negociación que llevó a la firma de los acuerdos de paz.

En este contexto, de historia reciente de nuestro país, los derechos civiles y políticos, incluídos los relacionados con la comunicación y la expresión (derecho a escuchar y ser escuchado, a informar y ser informado, derecho a ver y ser visto, a expresarse por escrito, etc.), no sólo fueron violados, sino que prácticamente se convirtieron en derechos prohibidos para la mayoría de la población. La cronología de la violencia, descrita por el Informe de la Comisión de la Verdad, indica que ésta (la violencia) obedecía a una concepción política que equiparó opositor político, subversivo 
y enemigo. Quien tenía ideas contrarias a las oficiales, corría el riesgo de ser eliminado como si fuese un enemigo armado en el campo de batalla. La prensa escrita salvadoreña contribuyó a difundir esta concepción al referirse al opositor como enemigo, guerrillero, terrorista o subversivo. El marco de una sociedad dividida y en conflicto, pues, ha sido el principal obstáculo para un ejercicio efectivo de los derechos civiles y políticos. Ha sido el principal obstáculo para que la sociedad civil haga uso real y eficaz de la libre comunicación y expresión. El conflicto armado terminó, gracias a los acuerdos, pero la división social (producto de la injusta distribución de los bienes) sigue presente y de hecho es fuente de nuevos conflictos.

En lo que respecta a la forma cómo han funcionado los medios de difusión en el contexto de la sociedad salvadoreña, ha existido lo. que pudiera llamarse una censura estructural: la mayor parte de los medios de comunicación masiva y, ciertamente, los más potentes, pertenecen al mismo sector social minoritario que dispone del poder económico, en íntima alianza con el poder estatal (Martín-Baró citando a Del Valle y otros, 1989). En consecuencia, de ninguna manera se pueden concebir como simples medios transmisores ajenos a intereses políticos, ideológicos y económicos; al contrario, los medios de comunicación colectiva, al informar, al dar criterios, opiniones o comentarios, al entretener, al promover publicitariamente bienes y servicios, o al hacer la suma de todo lo anterior, lo hace desde una opción específica, esa opción ha sido -en el caso salvadoreño- en favor de los grupos sociales minoritarios con mayor poder político, militar o económico (ver Stein, 1979).

¿Y qué ha pasado con el sentir de las mayorias? Pues bien,lo que realmente piensa la mayor parte de la población salvadoreña, se ha ignorado u ocultado ; los medios de comunicación se han limitado a presentar como opinión pública lo que era simplemente opinión interesada de sus propios propietarios o de vender como sentir colectivo lo que no pasaba de ser una opción muy particular (ver Martín-Baró, 1989). Los intereses y la vida real de las grandes mayorias han estado y están escasamente representados. Es cierto que han existido - y hoy parecen florecer- experiencias valiosas de comunicación altemativa; recordamos a YSAX durante la década del setenta y parte de la década del ochenta (sobre todo en 
tiempos de Monseñor Romero), el trabajo de periódicos como La Crónica del Pueblo y El Independiente. Estas experiencias se pusieron al servicio de la verdad de lo que ocurría en el país y abrieron espacios a la voz de las mayorías. Sin embargo, su presencia en la sociedad civil fue muy difícil y, en ciertos momentos, imposible; ésto debido a presiones gubernamentales y paragubernamentales de todo tipo: atentados dinamiteros contra las instalaciones de los citados medios, cierre obligado de los periódicos considerados de oposición, persecución y asesinatos de periodistas. Este cierre de los espacios de comunicación y de expresión, no sólo afectó a los medios de comunicación masiva alternativos, sino también a las instituciones (religiosas y educativas) organizaciones no gubernamentales, partidos políticos y personas que pudieran representar un análisis objetivo y crítico de la realidad, así como una identificación con los sectores populares (ver Equipo de trabajo, 1982).

En estas condiciones lo alternativo se tomó obligadamente clandestino. Entre 1981 y 1982, las presiones fueron llevadas a tal extremo, que imposilitaron la circulación y difusión de los puntos de vista críticos a los intereses del capital y del régimen. Es precisamente este el contexto en el que surgen los medios de comunicación cladestinos del FMLN, entre los que destacan Radio Venceremos y Radio Farabundo Martí. Su labor, no obstante, fue predominantemente agitativa y propagandítica, más que lo que propiamente podríamos llamar comunicación alternativa.

Con la instauración del proyecto contrainsurgente en 1983 y las exigencias de ofrecer una formalidad democrática, se abrieron unos paradójicos espacios para la comunicación. El más notorio lo constituye, sin duda, la aparición de los noticieros televisivos. Esto permitió una visión menos unilateral y más crítica de la realidad nacional (ver Martín-Baró, 1989).

Ahora que El Salvador ha entrado en un proceso de democratización, se espera que ésta (la democracia) pase también por el ámbito de la comunicación social. Y ya ha comenzado a pasar pero no con la suficiente profundidad. En tal sentido cierto es, por ejemplo, que los distintos institutos políticos y sus respectivas fracciones parlamentarias ejercen hoy -con más garantías que antes de los acuerdos- sus derechos a la organización, a la expresión y libre difusión de sus ideas. Cierto es que hoy las organizaciones sindi- 
cales, populares, culturales y grupos sociales tienen más posibilidades de indagar, cuestionar, criticar, denunciar y discrepar; sin que por eso se ponga en peligro inminente la vida de personas e instituciones. Un reciente caso de ello lo constituyen las denuncias -con nombre y apellido- de robos, desfalcos, secuestros, enriquecimientos ilícitos, evasión de impuestos, tráfico de influencias, espionaje telefónicos, etc., cometidos por individuos o instancias vinculadas al gobierno o grupos de poder; que hoy se conocen abiertamente por parte de la ciudadania. Por supuesto, que la sola denuncia no basta, hay que pasar a la efectiva erradicación y castigo de los culpables, pero eso, ya es responsabilidad de los ejercen el poder político y judicial, así como de los encargados de la seguridad pública.

Cierto es también que en el nuevo escenario político han aparecido nuevo medios (con un buen grado de pluralidad y profesionalismo) y varios de los antiguos han iniciado cambios importantes - ya sea por razones de competencia o por influjo del proceso democráticos, o por ambas - en sus formatos y contenidos informativos.

Hay pues, elementos y espacios positivos nuevos, tanto en la realidad política salvadoreña, como en el ámbito de la comunicación y expresión. Estos espacios deben seguirse cultivando para avanzar más en la apertura iniciada. Pero, lo que de positivo hay en esta línea o el acento que suele ponerse en la misma, no debe hacernos perder de vista dos hechos fundamentales: primero, la comunicación y libre expresión como un derecho de la sociedad civil y de sus distintas agrupaciones sociales (asociaciones, cooperativas, sindicatos, gremios, organizaciones no gubernamentales, etc.), todavía no presentan, al menos, un cierto grado aceptable de realización; segundo, la prensa, la radio y la televisión en general, aún no dan cabida igualitaria a todos los puntos de vista. El acceso de la sociedad civil a los medios está, si no vetado, por lo menos muy reducido.

Una reflexión crítica del "fin social" que de hecho observamos en los medios de difusión masiva, en nuestro país, nos proporciona argumentos básicos para sustentar nuestra posición. El "fin social" predominante - aunque no único - de los medios se ha centrado y se centra en dos aspectos: En primer lugar, los medios siguen siendo configuradores y trasmisores de ideología (domi- 
nante), actuando así como verdaderos agentes culturales en la colectividad. Son generadores de sentido, brindando constantemente elementos para interpretar la realidad (ver Stein,1979). De tal inanera que éstos (medios de difusión) definen elespacio de la escena pública y son un recurso clave de control social y de legitimación del orden social. En principio, lo que aquí afirmamos no tiene necesariamente una connotación negativa. Toda sociedad demanda un conjunto de instancias y agentes que den cohesión y estabilidad social. La crítica se deriva del hecho de que ese "fin social", se pone al servicio de un modo de organización social, político y económico donde las necesidades básicas de la mayor parte de ciudadanos están insatisfechas; donde los derechos civiles, sociales y culturales de esas mayorias, son estructuralmente violados; donde sectores minoritarios utilizan en provecho propio los bienes y recursos disponibles. Se busca legitimación para un orden injusto (lo que es éticamente inaceptable) y se ejerce control social para asegurar una cohesión que más bien es sometimiento (lo que es contrario a la democracia).

El segundo aspecto en el que centra el "fin social" de la mayoría de medios de difusión masiva, es el relacionado con la actividad lucrativa. A ésta suelen supeditarse importantes actividades relacionadas con la generación y circulación de mensajes (informativos, formativos o de entretenimiento). Los medios de difusión son concebidos como un negocio y la proyección social de éstos es entendida como la posibilidad que se ofrece a los consumidores de conocer una variedad de productos y servicios. Sin importar, la mayoría de las veces, la calidad de lo que se ofrece ni la satisfacción del cliente. ¿ Por qué van a permitir - los medios de difusión-denunciar o censurar la mala calidad de algunos productos o servicios (o la publicidad y propaganda extremadamente manipuladoras) si de la cantidad de anuncios emitida en su medio depende su propia subsistencia? En consecuencia, los millones que se invierten en publicidad de hecho limitan y condicionan, el uso de los medios de difusión, así como los derechos a la libre comunicación y expresión.

No se crea que nuestra pretensión es que los medios que funcionan como empresas comerciales dejen de serlo. No se trata de eso, pero sí de que se establezca un justo equilibrio entre la activi- 
dad propiamente lucrativa y las responsabilidades que tienen los medios ante la sociedad como totalidad. Al oyente, al televidente o al lector no puede reducirseles a ser sujetos potenciales o reales de consumo. La democracia vivida en el campo de la comunicación, no puede permitir una práctica a ultranza y sin regulación de la filosofía y las técnicas del márketing (no se debe buscar sólo el beneficio económico a través de la venta agresiva). La actividades propias de la difusión y comunicación colectivas no deben estar en función o subordinadas a la lógica del mercado y sus intereses. Concebir los medios de difusión y comunicación como un buen negocio (manejado por pocas manos bien conocidas) es otra de las tantas formas de minar la democracia. En el país, hemos tenido antecedentes preocupantes en este sentido. Recordamos, de paso, las protestas realizadas por la Asociación Salvadorena de Medios Publicitarios (ASMP) y la Asociación Salvadoreña de Radiodifusores (ASDER), a raíz de las regulaciones - a las campañas electorales- que establecía el nuevo código electoral. Las dos asociaciones se opusieron con mucha radicalidad a dos artículos específicos: el $\mathbf{2 2 8}$ que prohibía lesionar la moral, el honor o la vida privada de candidatos o líderes muertos; y el 229, específicamente, el inciso que regulaba la difusión de la propaganda electoral mediante la determinación de horas o franjas de tiempo destinadas para tal fin. Cuando los partidos políticos discutieron y aprobaron el nuevo código, incluyendo los artículos mencionados, pretendian que la ley electoral posibilitara: una campaña de altura ética y política,equidad en la competencia electoral, garantía de la libre expresión y protección de la salud mental de la ciudadanía. Sin embargo, para ASDER y ASMP tales artículos eran inconstitucionales, porque desde su modo particular de pensar, éstos violaban los derechos de libre emisión del pensamiento y de contratación. No obstante, los artículos en mención estában en plena coherencia con las regulaciones, que en esta materia, estipula la Constitución Política del país (ver artículo 6 de la Constitución).

¿Qué es lo que puso, entonces, en pie de lucha a los propietarios de estos medios de difusión y publicidad? Ciertamente, no fue su celo por la constitucionalidad y el estado de derecho; ya que su protesta era contraria al espíritu y letra de la ley. La respuesta podemos encontrarla en otro lugar: las campañas electora- 
les han representado una verdadera "mina de oro" para los propietarios de las grandes empresas de difusión colectiva y de las agencias de publicidad. Para poner un ejemplo, sólo el partido ARENA gastó más de 12 millones de colones,en propaganda por televisión, durante la primera vuelta de las elecciones de 1994 (de noviembre del 93 a marzo del 94). Telecorporación Salvadoreña, canales 2,4 y 6 (TCS), recibió el 90 por ciento de la inversión publicitaria de ARENA (ver Obach, 1994).

En este marco de compra y venta de espacios, las disposiciones que establecía el código no constituían una amenaza a los derechos de los ciudadanos y de los partidos políticos, tampoco era una amenaza para la libre contratación, pues los partidos políticos podían negociar - con los respectivos medios - los espacios que estimaran convenientes dentro de las franjas estipuladas. Pero sí, constituían una disminución importante de los ingresos, que los empresarios dedicados al "negocio" de los medios de difusión, ya habían contabilizado a favor de su patrimonio. Al final -en perjuicio de la democracia- predominó el pragmatismo empresarial. Los medios fueron saturados de propaganda, hubo gran desproporción en el acceso a los espacios entre los diferentes partidos políticos (dominó la propaganda del partido en el gobierno), las instituciones y medios de difusión identificados con la ideología tradicional de ARENA, recurrieron al uso de la polarización en la campaña electoral (ataque y desprestigio del adversario); la amenaza y el miedo, que prevaleció durante la guerra, volvieron a percibirse en los meses de la campaña. La fuerza del poder económico e ideológico, no permitieron la posibilidad de igualdad de condiciones en la competencia electoral, tampoco un uso democrático de la libertad de expresión, ni el cuido de la salud mental de la ciudadanía.

Después de este rápido rastreo de lo que, desde nuestra perspectiva, ha sido y es la práctica de los derechos a la comunicación y a la expresión; pasamos ahora a mostrar cuáles condiciones son necesarias para favorecer su realización histórica, con mayor apego a lo verdadero y justo, tanto de los contenidos teóricos implícitos en ambos derechos, como de las exigencias que plantea - en esta área - el proceso de democratización de la sociedad salvadoreña. 
4. A modo de conclusión: condiciones para un ejercicio efectivo de los derechos a la expresión y a la comunicación.

Dartimos del supuesto de que la verdad y la vigencia de estos 1 derechos, estará dada por sus concreciones prácticas y no tanto por su sola formulación y defensa teóricas. Por consiguiente, proponemos un conjunto de condiciones básicas, sin las que no es posible un cierto grado de realización de los valores que supone e implica una comunicación democrática.

(a) El estado -como principal garante de estos derechos- deberá poner los medios, legales y políticos, que posibiliten un ejercicio real de los mismos a los diversos sectores sociales del país, especialmente, a los grupos mayoritarios. Es decir, deberá garantizar el acceso a la recepción y a la expresión de todos los ciudadanos, evitando que el ejercicio efectivo de la expresión y la comunicación sea privilegio de pocos. El gobierno y los propietarios de los principales medios de difusión masiva, suelen hablar de la libertad de opinión y de prensa, como derechos fundamentales y como condición indispensable de la democracia; pero si esa libertad de opinión y de prensa sólo la pueden ejercitar quien posee medios no adquiribles por las mayorías, resulta entonces que la libertad de prensa y de opinión es un pecado fundamental y una condición que hace imposible la democracia: si un periódico, una radio o una emisora de televisión sólo pueden ser sostenidas por un gran capital y sólo pueden subsistir con el apoyo de los anunciantes, que representan las fuerzas del capital, la libertad de prensa así ejercida es la negación de lo que proclama el derecho (ver Ellacuría, 1976). Por el contrario, la realidad estará ajustada al derecho, si existen condiciones (legales y materiales) para que tales libertades sean patrimonio sino de todos, si de la mayor parte de la población. Esto supone, democratizar la palabra y a su vez, transformar uno de los principales obstáculos que enfrentan los verdaderos procesos democráticos: la concentración de los bienes y servicios. Un buen ejemplo y antecedente de lo que aquí proponemos, lo constituye -en el campo de la radiodifusión- el reciente decreto de ley aprobado por el gobierno de Colombia (agosto de 1994), por el cual se reglamenta el servicio comunitario de radiodifusión sonora. La nueva ley colombiana da legitimidad a muchos radiodifusores comunitarios, que venían laborando sin permiso ofi- 
cial; al autorizarles potencias en AM y FM hasta 500 vatios. Además, permite la publicidad comercial en dichas radios y las transmisiones enlazadas. En Colombia, pues, ya se le ha dado un marco legal a la voz de la sociedad civil. Este ejemplo debería ser imitado por los legisladores de nuestro país, sobre todo si tomamos en cuenta que en los últimos tres años, en El Salvador también se han levantado antenas populares (actualmente existen más de diez radios comunitarias a lo largo y ancho de la geografía nacional), que reclaman legitimidad y fin del monopolio de la palabra. También debería ser imitado por la Asociación Salvadoreña de Radiodifusores - ASDER - quienes, por un lado, suscriben declaraciones en las que se pide promover el mayor número de periódicos, revistas, radios, canales de televisión y videos que reflejen la gama más amplia posible de opiniones de la sociedad (Declaración de Santiago, mayo de 1994); y, por otro lado, se pronuncian en contra de la operación de las emisoras llamadas (por ellos) clandestinas y/o comunales que están proliferando en Centro América, sin permiso oficial para operar (ASDER, Memoria de labores 1993/1994). Grave incoherencia entre lo que suscriben a nivel continental y lo que realmente buscan a nivel regional y nacional.

(b) El contexto político y social que ha de acompañar la práctica de los derechos aquí tratados, deberá ser pluralista y participativo. Pluralista, en tanto se han de abrir espacios, en los procesos de comunicación, a los distintos intereses legitimos (que no atentan contra el bien común), así como a los sectores que los representan. Participativo, en cuanto que todos los actores sociales, deberán tener la posibilidad de ejercer su derecho a informar y ser informado, a dar libremente su opinión y, a comunicarse a través de las diferentes formas y medios. Los principios y condiciones de la gestión del actual gobierno, aseguran que la construcción de un nuevo El Salvador, pasa -entre otras cosas- por la apertura democrática. Esto es, fomentando el amplio desenvolvimiento de todas las corrientes de pensamiento, cultivando la racionalidad histórica y terminando con la época de dogmas y fanatismos (ver Calderón Sol, 1994). Aunque la realidad del discurso todavía no ha cambiado en esa dirección, el horizonte hacia el que apuntan estas medidas podría favorecer -si éstas últimas se llevan a la práctica- al proceso democratizador en el ámbito de la comunicación y la expresión. 
La sociedad civil debería tomarle la palabra al gobierno en este sentido. Sería una buena prueba para constatar, si en este campo, hay voluntad política para cumplir con lo prometido. Para constatar si el discurso es para realizarlo en la práctica o simplemente para vender una buena imagen hacia el exterior.

(c) Los medios masivos, en tanto instrumentos de la libre expresión y comunicación, deben cumplir con un fin social genuino. Esto significa, que es necesario reorientar o redimensionar la función principal que de hecho han ejercido la mayoría de medios: ser promotores del consumo y propulsores de la adhesión a un orden antidemocrático, Hoy día, por ejemplo, a raíz de la globalización del modelo neoliberal, los medios estrictamente comerciales promueven una sola cultura: la del mercado, la competencia, la eficacia, la individualidad y el pragmatismo. El lenguaje del mercado se ha constituido en el gran regulador y referente de la vida social, lo que no fortalece al mercado es considerado marginal, secundario y obsoleto (ver ALER, 1994). Frente a esta realidad, el genuino fin social de los medios estaría dimensionando otro tipo de necesidades y valores, tales como: énfasis en la problemática relacionada con la vida e intereses de las mayorías, fomento de la participación del movimiento social (sindicatos, cooperativas, asociaciones, iglesias, universidades, etc.) en orden a posibilitar el paso de una actitud colectiva indiferente o pasiva, a una actitud responsable ante los nuevos retos histónicos; fomento de la cultura del debate, que requiere el auténtico ejercicio de la libre expresión y comunicación, así como el desarrollo de una conciencia colectiva bien informada y formada. En el contexto neoliberal de total privatización (incluyendo el uso y función de los medios), la real democratización de la sociedad demanda, que el interés económico que suele ser dominante en la mayoría de medios comerciales, no debe anular una auténtica función social. El afán de lucro no puede convertirse en el fin último de la comunicación y difusión social. Recordemos que en la comunicación está en juego algo verdaderamente humano: nuestra capacidad de construimos como personas y como sociedad. A este propósito debería supeditarse todo lo demás.

(d) En un contexto de refundación y reconciliación social -como el que se pretende en El Salvador- los derechos a comunicarse y expresarse han de estar orientados hacia el compromiso con la 
verdad y, hacia el respeto y promoción de la vida humana. La realidad del país y la práctica de la democracia en este ámbito, conllevan la obligación ética de impulsar el proceso democratizador desde y con la verdad. En consecuencia, los distintos actores sociales, la clase política y los medios de difusión y comunicación en general, deberán diferenciar entre lo que es la realidad y lo que podría ser una interpretación interesada (manipulada) de la misma; deberán distinguir entre lo que es información y lo que es propaganda; reconcer lo que es interés del conjunto de la sociedad y lo que no pasa de ser interés particular o, peor aún, egoísta; delimitar lo que es nacional y lo que es partidarista; deberán superar el simplismo cognoscitivo - producto del fanatismo, el dogmatismo, el sectarismo, el partidismo; es decir, de una profunda ideologización- que por no matizar la realidad ha conducido y conduce a interpretaciones y acciones funestas. Institucionalizar la verdad y desterrar la mentira, pues, es uno de los principales retos que habrá de enfrentar la democratización de la comunicación. La opción por la verdad requerirá también, de un gran esfuerzo de racionalidad, honestidad y valentía, que dé cuenta de la realidad histórica (pasada y presente) que más ha configurado la estructura y sentido de nuestra sociedad. El Informe de la Verdad es un importante antecedente en este sentido. Pero, junto a la búsqueda y el anuncio de la verdad, es también imperativo que los derechos a la comunicación y a la expresión, se canalicen de cara a promover uno de los valores más maltratados durante la guerra y con más riesgos en la postguerra: la vida y dignidad de las personas. El fin del conflicto armado, frenó el número de víctimas que éste producía. No obstante, en la actualidad preocupa la precariedad de la vida humana, a causa de la violencia institucionalizada (injusticia social, coerción del gobierno e irresponsabilidad de los órganos del estado), la violencia delincuencial (crimen común u organizado) y, en ciertos casos, por violencia de la guerra sucia. El escenario de la postguerra plantea una seria exigencia a las instancias antes mencionadas: propiciar la cultura de la vida frente al predominio de la cultura de muerte. Esto es, frente a la miseria, las distintas formas de opresión y discriminación, la corrupción, la depredación del medio ambiente, la delincuencia, etc.; se debe trabajar por comunicar, difundir y consolidar: la justicia social, la opción por los más débiles, la honestidad, la austeridad, el bien común, la seguridad 
ciudadana, los derechos sociales, la desmilitarización y demás valores que salvaguarden la vida en sus diferentes manifestaciones.

(e) Uno de los modos principales que tiene la población, para conocer la realidad y tomar posición ante ella, es a través de la imagen pública que proyectan los distintos medios de difusión. Por consiguiente, tales medios tienen una enorme responsabilidad en la generación u obstrucción de los procesos sociales que afectan a la totalidad del país. No cabe duda, de que en El Salvador uno de los procesos más decisivos de la presente fase, lo constituye la transición hacia la democracia pluralista y participativa, impulsada por los acuerdos de paz. Desde su propia especificidad, dichos medios pueden y deben contribuir a lo que hoy representa uno de los retos de mayor importancia para la nación: la democratización política y económica. Algunas de las actitudes y procesos que se deberían cultivar, por parte de los medios en cuestión, de cara a esta nueva fase por la que atraviesa el país, son los siguientes: sigue siendo necesaria una mayor y mejor capacitación profesional, para poder cumplir con una de las misiones centrales que la colectividad espera de los medios, esto es, captar plena y objetivamente la realidad y comunicar esa captación de la mejor forma posible al público; al disminuir las presiones propias del conflicto armado, se está en mejores condiciones para ejercer una labor comunicativa más independiente, creadora y crítica; el nuevo contexto puede permitimos una mayor objetividad en la selección y jerarquización de las informaciones, según la trascendencia que tengan para el país y no según lo que favorezca o desafavorezca la ideología del medio; mediante los contenidos y formatos utilizados, se puede contribuir a la distensión y reconciliación social, fomentando la tolerancia con las personas y la flexibilización y apertura de las propias posiciones (sin llegar a la tolerancia a ultranza, que pacta con la mentira y la injusticia); se deberá contribuir a la promoción de la identidad nacional, que recupere y relance los propios valores (la identidad nacional se ha confundido con modelos políticos, económicos y culturales, que no responden a la realidad salvadoreña); sigue también siendo necesario, estimular la inteligencia de los interlocutores colectivos, que permita a las personas y grupos sociales, pasar de una actitud acrítica a una actitud crítica, de una actitud pasiva o indiferente a una actitud de sujeto histórico, de una actitud indivi- 
dualista a una actitud solidaria. Es necesario favorecer estas actitudes y procesos, en tanto que la construcción de la paz no termina con la firma de los acuerdos. La refundación de las bases para un nuevo patrón histórico de convivencia social y la búsqueda de una auténtica estabilidad por medio de la concertación, sigue siendo una tarea permanente, en el que la sociedad civil debe tener un papel preponderante.

(f) Quizás pudiera pensarse, que las tareas antes señaladas competen más bien a los medios que denominamos alternativos. Es lógico pensar de esa manera, pues la mayoría de medios existentes en nuestro país, no han impulsado una labor comunicativa que favorezca la participación de la sociedad civil. No han desarrollado, en el sentido estricto, una experiencia de comunicación donde el emisor y el interlocutor cumplan alternativamente ambas funciones. No obstante, el actual proceso de democratización demanda de los diferentes medios, avanzar en su propio proceso de re-ordenamiento y de re-orientación en lo que respecta a su fin social. Estamos en un buen momento para oír y tomar en cuenta la opinión de las mayorías, en el momento de respetar el derecho de la colectividad a no ser manipulado ni confundido con visiones distorsionadas o malitencionadas de la realidad. Es el momento de deponer los intereses contrarios al bien común, a la racionalidad y a la convivencia justa. Los retos que presenta esta nueva realidad no deberían ser privativos de los medios que conocemos como alternativos. Claro está, que de aquellos medios que por principio buscan la democratización de la palabra, o que aparecieron a la luz y en el contexto del proceso de paz; se espera un mayor esfuerzo y ejemplo en esta línea de acción.

(g) La democratización de la sociedad y de la comunicación pueden ser fortalecidas, si las experiencias -que como dijimos arriba hoy parecen florecer- de medios alternativos encuentran espacios de desarrollo y crecimiento. Entendemos por alternativos aquellos medios cuya orientación presenta los siguientes rasgos: son populares, esto es, mantienen un vínculo estrecho con la mayor parte de la sociedad $y$, tienen en cuenta la vida misma de la gente en su integridad (necesidades, afectos, gustos, intereses); son participativos, es decir, posibilitan un tipo de relación -entre emisores y perceptores- lo más horizontal posible, para que exista un verdadero diá- 
logo, asimismo, da el poder de la palabra a todos los sectores sociales, especialmente, a los que históricamente se les ha marginado de la misma por estructuras sociales y políticas; ejercitan el pluralismo, en tanto están abiertos a todos los sectores sin distinción ni discriminación; contribuyen a mejorar la calidad de vida de las mayorías (son el lugar natural de las campañas de salud, nutrición, educación, protección del medio ambiente, promoción de los derechos humanos, etc.); pretenden la excelencia profesional, tanto en lo técnico como en los contenidos, para saber responder a las exigencias de los nuevos tiempos; potencian el desarrollo de una conciencia crítica, en la medida en que estimulan el razonamiento, el análisis, la polémica, la argumentación y el debate, como mecanismos generadores de una cultura democrática; proponen nuevos temas en la agenda pública y política, de tal forma que lo urgente y coyuntural, no supedite lo más importante y estructural de la realidad (ver ALER, 1994). La práctica de un tipo de comunicación con estas características, no sólo favorecerá al proceso de democratización de la sociedad salvadoreña, sino también al necesario proceso de reconciliación social que aún sigue pendiente.

(h) El trabajo que se espera de los medios alternativos, no está exento de limitaciones y riesgos. Limitaciones de naturaleza legal y comercial: por una parte,todavía no existe un marco jurídico que asegure los legítimos intereses de la comunicación altemativa en sus diferentes modalidades y, por otra parte, se da un boicoteo (latente o manifiesto), por parte de las agencias de publicidad, que no permite que los comunicadores alternativos se conviertan en instancias administrativas eficientes y sanas económicamente hablando. Los riesgos vienen dados, cuando la propia labor comunicativa se realiza en el marco de los principios y valores del mercado; éste puede convertirse en un modo de pensar y operar en base a sus categorias de competitividad, puede convertirse en lugar de realización personal o institucional; desnaturalizando las opciones fundamentales de la comunicación alternativa (ver Mata, 1994). Por eso, la inserción en el mercado exige una seria y constante actitud crítica sobre el trabajo alternativo de la comunicación.

En la puesta en práctica de condiciones como las señaladas, es dónde se medirá el grado de verdad o falsedad de las formulaciones y planteamientos abstractos. Aquí es dónde se verá si el derecho 
proclamado tiene un carácter de bien común, o si es un mecanismo ideológico que justifica y esconde el privilegio de sectores minoritarios y excluyentes.

\section{Referencias bibliográficas}

Acuerdos de El Salvador: en el camino de la paz (1992). Naciones Unidas.

ALER (1994). Hacia un nuevo horizonte teorico. IX Asamblea General Ordinaria. Quito.

Calderón Sol, Armando (1994). "Discurso de toma de posesión". En Estudios Centroamericanos (ECA), 547-548, 601-607.

Constitución Polftica de El Salvador, 1983. "De la locura a la esperanza. La guerra de los doce antos en El Salvador. Informe de la Comisión de la Verdad para El Salvador" (1993). En Estudios Centroamericanos (ECA), 533, 162-326.

Declaración de Santiago (1994). Seminario sobre el desarrollo de los medios de comunicación y la democracia en América Latina y El Caribe. Santiago de Chile.

Declaración Universal de Derechos Humanos.

Editorial (1993). “¿Son libres las elecciones de 1994?”. En Estudios Centroamericanos (ECA), 539, 801-812.

Ellacurla, Ignacio (1976). "Historización del concepto de propiedad como principio de desideologización". En estudios centroamericanos (ECA) Pág. 406, 791; 800.

Ellacurfa, Ignacio (1982). "Universidad, derechos humanos y mayorfas populares". En Estudios Centroamericanos (ECA), 406, 791-800.

Ellacurla, Ignacio (1990). "Historización de los derechos humanos desde los pueblos oprimidos y las mayorías populares". En Estudios Centroamericanos (ECA), 502, 589-596.

Equipo de trabajo del departamento de letras de la UCA (1982). "Los medios de comunicación un arma más en la contienda". En Estudios Centroamericanas (ECA), 403-404, 467-492.

Martín-Baró, Ignacio (1989). "Los medios de comunicación masiva y la opinión pública en El Salvador". En Estudios Centroamericanos (ECA), 493-494, 1081-1093.

Mata, Marfa cristina (1994). "Hacer radio es producir realidad". Quito. (Mimeo).

Obach, Xavier (1994). “ ¡Patria o gente! Análisis de la campaña televisiva de ARENA y de la Coalición". En Estudios Centroamericanos (ECA), 545-546, 213-256.

Oller, M. Dolors (1994). Ante una democracia "de baja intensidad" la democracia por construir. Barcelona: Cristianisme i justícia.

República de Colombia (1994). Ministerio de Comunicaciones. Decreto número 1695, por el cual se reglamenta el servicio comunitario de radiodifusión sonora.

Sámour, Héctor (1994). "Marco térico político para la construcción de un orden democrático en El Salvador". En Estudios Centroamericanos (ECA), 543-544, 33-55.

Stein, Eduardo (1979). 'Los medios de comunicación colectiva en El Salvador ante las exigencias del Diálogo Nacional". En Estudios Centroamericanos (ECA), 369-370, 647-672. 